ORIGINAL ARTICLES

\title{
Prognostic value of stress echocardiography in women with high $(\geqslant 80 \%)$ probability of coronary artery disease
}

\author{
J I Davar, E B Roberts, J G Coghlan, T R Evans, D P Lipkin
}

\begin{abstract}
Objective-To assess the prognostic significance of stress echocardiography in women with a high probability of coronary artery disease (CAD).

Setting-Secondary and tertiary cardiology unit at a university teaching hospital. Participants-A total of 135 women (mean (SD) age 63 (9) years) with pre-test probability of $\mathrm{CAD} \geqslant 80 \%$ were selected from a database of patients investigated by treadmill or dobutamine stress echocardiography between 1995 and 1998 .

Main outcome measures-Patients were followed up for occurrence of subsequent cardiac events (cardiac death, myocardial infarction, admission with unstable angina, and revascularisation) using a structured telephone interview and case note review.
\end{abstract}

Results-Each patient had between two and seven (mean 3.5) CAD risk factors and pre-test probability of CAD $\geqslant 80 \%$. Ninety three patients $(68.9 \%)$ had negative stress echocardiography. Mean (SD) follow up was 20.1 (8.5) months. There were six events in the positive stress echocardiography group (two cardiac deaths, one unstable angina, three revascularisations), and one event in the negative stress echocardiography group. Cox regression analysis showed positive stress echocardiography $(p=0.02)$ and age $(p=0.03)$ to be the only univariate predictors and positive stress echocardiography to be the only independent predictor of future cardiac events (relative risk 8.9, confidence interval 1.0 to $76.5, p=0.04)$. Cumulative event free survival to 38 months was $98 \%$ in the negative stress echocardiography and $50.7 \%$ in the positive stress echocardiography groups.

Conclusion-In women with high pre-test likelihood of CAD: (1) negative stress echocardiography identifies a subgroup with low risk of cardiac events who do not require further invasive investigation and (2) positive stress echocardiography identifies a subgroup with increased risk of subsequent cardiac events.

(Postgrad Med F 2001;77:573-577)

Keywords: coronary artery disease; women; stress echocardiography
Assessment of clinical symptoms and risk factors is essential for evaluation of patients presenting to a physician. The predictive value of clinical risk factors and presenting chest pain syndromes differs between men and women. ${ }^{1-3}$

Coronary Artery Surgery Study data demonstrated that $83 \%$ of men but only $50 \%$ of women presenting with chest pain of sufficient severity to undergo coronary angiography had significant coronary artery disease (CAD). ${ }^{4}$ Overall, angina is more frequent on presentation in women than in men, ${ }^{5}$ but prevalence of significant CAD is lower, ${ }^{67}$ and prognosis is more benign. ${ }^{89}$ While electrocardiography is of limited diagnostic and prognostic value in women, ${ }^{10}$ stress echocardiography is both sensitive and specific for the diagnosis of CAD and has been proposed as a cost efficient initial diagnostic test in this group of patients. ${ }^{12}$

The prognostic value of stress echocardiography has been investigated in mixed gender populations, ${ }^{13-15}$ with limited attention to risk stratification in women. ${ }^{16}{ }^{17}$ Studies confined to women have assessed the prognostic value of stress echocardiography in groups with a mixed pre-test CAD risk profile, a significant number of patients being in a low risk group. Only one study has evaluated the prognostic value of dobutamine stress echocardiography in women with a specific pre-test risk of CAD: women with intermediate probability of CAD. ${ }^{18}$

The aim of our study was to assess the prognostic value of stress echocardiography in women with high probability ( $\geqslant 80 \%$ ) of CAD.

Subjects and methods

PARTICIPANTS

Between January 1995 and January 1998 stress echocardiography (dobutamine or treadmill) was performed on 1021 patients with known or suspected CAD. Patients had been referred for investigation of suspected angina, assessment of functional significance of angiographically proved $\mathrm{CAD}$, and evaluation of myocardial viability. From this cohort, 135 women with a pre-test probability of CAD $\geqslant 80 \%$ but no preceding diagnosis of CAD and no resting wall motion abnormalities were identified retrospectively. Inconclusive studies were excluded from analysis (that is, terminated test at $\leqslant 85 \%$ of target heart rate with absence of new or worsening wall motion abnormality). Pretest risk assessment was based on profiles allowing estimation of the likelihood of CAD as being low $(<20 \%)$, moderate $(20 \%-80 \%)$, or 
high ( $>80 \%$ ), based on a combination of clinical risk factors. ${ }^{3}$ If a patient had stress echocardiography more than once, only the first test was entered into the analysis.

STRESS ECHOCARDIOGRAPHY

A baseline electrocardiogram, blood pressure, and a two dimensional echocardiogram were recorded at rest. If it was felt that a patient was unable to exercise to full capacity, dobutamine stress echocardiography was used, in accordance with the guidelines of the American College of Cardiology/American Heart Association. ${ }^{19}$ Echocardiograms were recorded with the patient in the left lateral decubitus position. Two dimensional images of the parasternal long and short axes and apical four and two chamber views were obtained. Recordings were stored on optical discs and on VHS videotape. Images were digitised on-line with an $\mathrm{R}$ wave trigger to obtain a continuous loop using the EchoPac programme of the Vingmed CFM machine (Horten, Norway). For dobutamine stress echocardiography, cine-loops from baseline, low, intermediate, and peak stress stages were placed on a quad screen format for analysis. For treadmill stress echocardiography, cine-loops from baseline and peak stress were placed side by side for analysis.

Treadmill stress echocardiography was performed using the Bruce protocol, post-exercise images being obtained within 90 seconds of exercise termination.

For dobutamine stress echocardiography, electrocardiograms and two dimensional echocardiograms were monitored continuously and blood pressure was measured at three minute intervals. Dobutamine was infused through a peripheral intravenous line using a mechanical pump starting at a dose of $5 \mu \mathrm{g} / \mathrm{kg} /$ min and increasing to $10,20,30,40$, and 50 $\mu \mathrm{g} / \mathrm{kg} / \mathrm{min}$ at intervals of three minutes until an end point was reached. If the target heart rate was not achieved ( $\geqslant 85 \%$ of maximum predicted) the final stage was prolonged to a maximum of five minutes, and/or atropine was added in bolus doses of $300 \mu \mathrm{g}$, up to a maximum of $1500 \mu \mathrm{g}$.

Test end points were: $\geqslant 85 \%$ of maximum predicted heart rate; development of severe and/or extensive new wall motion abnormalities; horizontal or downsloping ST changes of $>0.2 \mathrm{mV} 80 \mathrm{~ms}$ beyond the J point; new ST elevation; severe angina; fall of systolic blood pressure $>40 \mathrm{~mm} \mathrm{Hg}$ from baseline or to $<90$ $\mathrm{mm} \mathrm{Hg}$ systolic; blood pressure $>230 / 120 \mathrm{~mm}$ $\mathrm{Hg}$; significant tachyarrhythmia; and intolerable side effects secondary to dobutamine.

The same operator (JID) reviewed all studies using the 16 segment model for wall motion analysis recommended by the American Society of Echocardiography. ${ }^{20}$ Tests were regarded as positive if there was evidence of new or worsening wall motion or thickening abnormalities. More than one segment needed to be involved to confirm ischaemia in the basal segments of the posterior circulation. ${ }^{21}$
FOLLOW UP

Patients were interviewed over the telephone by the same investigator (EBR). A structured question format was used. Occurrence and dates of admissions to hospital with chest pain syndromes, myocardial infarction, or coronary revascularisation were recorded. The hospital's medical and computerised records were reviewed to confirm the results of telephone inquiry and to record cardiac deaths. Coronary risk factor profiles were assessed for each patient, including total cholesterol, family history of CAD, smoking and menopausal status, and diagnosis of diabetes mellitus or hypertension. If any of the records were unavailable the patient's family practitioner was contacted for further information. Cardiac events were defined as myocardial infarction, admission to hospital with unstable angina, revascularisation, and cardiac death.

\section{STATISTICAL ANALYSIS}

Data are expressed as the mean (SD). To assess the risk stratification provided by stress echocardiography, Kaplan-Meier survival curves were generated.

The Cox proportional hazard model, with univariate and stepwise procedures, was used to evaluate the ability of variables to predict an event. Variables evaluated were age, family history of premature CAD, smoking status, history of hypertension, postmenopausal status, treatment with hormone replacement therapy, diabetes mellitus, positive or negative stress echocardiography result, number of coronary artery territories involved if stress echocardiography was positive, percentage of maximal heart rate achieved if stress echocardiography was positive, and wall motion score at peak exercise if stress echocardiography was positive.

\section{Results}

The mean age of the study population was 63 (9) years (range 30-85 years). Each patient had on average 3.5 (range 2-7) risk factors for CAD (table 1).

Treadmill stress echocardiography was carried out in 35 cases and dobutamine stress echocardiography in 100 cases. Ninety three women $(68.9 \%)$ had a negative stress echocardiogram. All patients in this group achieved $\geqslant 85 \%$ of maximal predicted heart rate. The mean age of patients with negative stress echocardiography was 61.5 (9.9) years (range

Table 1. Distribution of risk factors for coronary artery disease in the study group $(n=135)$

\begin{tabular}{lr}
\hline Risk factor & No (\%) \\
\hline Chest pain: classic angina & $46(34.0)$ \\
Chest pain: atypical angina & $54(40.0)$ \\
Cigarette smoking & $19(14.1)$ \\
Systemic hypertension $(>160 / 90 \mathrm{~mm} \mathrm{Hg})$ & $43(31.9)$ \\
Hypercholesterolaemia (total cholesterol & $74(54.8)$ \\
$\quad \geqslant 6.2 \mathrm{mmol} / \mathrm{l})$ & $64(47.4)$ \\
Age $>65$ years & $14(10.4)$ \\
Diabetes mellitus & $55(40.7)$ \\
Family history of premature coronary artery & $104(77.0)$ \\
$\quad$ Pisease & \\
\hline
\end{tabular}

HRT $=$ hormone replacement therapy. 


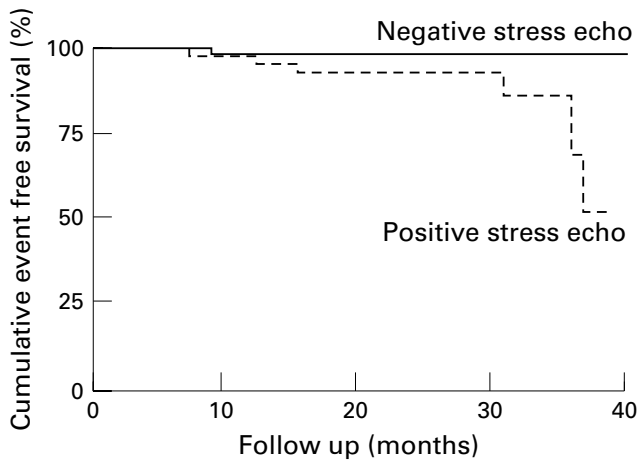

Figure 1 Cumulative event free survival to 38 months in women with positive and negative stress echocardiography (echo).

30-82 years) $v 67.5$ (9.7) years (range 43-85 years) in patients with positive stress echocardiography $(\mathrm{p}=0.002)$.

Follow up was completed in 134 cases. One patient was lost to follow up due to emigrating abroad. Two women with positive stress echocardiography and subsequent percutaneous transluminal coronary angioplasty (PTCA) within six months were excluded from analysis. The decision to exclude these cases was based on the possibility that positive stress echocardiography could have directly influenced the decision for angioplasty.

The final study group consisted of 132 women with high probability of CAD. Mean follow up was 20.9 (8.5) months (range 6-40 months).

There were seven events during the follow up period. Six events were in the positive and one in the negative stress echocardiography group. Events in the positive stress echocardiography group included two cardiac deaths, one admission with unstable angina, and three revascularisation procedures (PTCA). One patient in the negative stress echocardiography group had PTCA for gradually worsening angina 20 months after stress echocardiography.

Two variables were identified as univariate predictors of cardiac events: age $(p=0.03)$ and positive stress echocardiography $(p=0.02)$. None of the clinical variables was identified as a predictor of cardiac events.

Cox stepwise analysis showed positive stress echocardiography to be the only independent predictor of future cardiac events: relative risk 8.9 (95\% confidence interval 1.0 to 76.5 , $\mathrm{p}=0.04)$.

Cumulative event free survival rate to 38 months after stress echocardiography was $98.8 \%$ for patients with negative and $50.7 \%$ for patients with positive stress echocardiography ( $\log$ rank 5.5, $\mathrm{p}=0.0186$; see fig 1 ).

Average annual cardiac event rate was $0.4 \%$ in for women with negative compared with

Table 2 Heart rate and wall motion score among those with positive stress echocardiograms

\begin{tabular}{lccc}
\hline $\begin{array}{l}\text { Patients with positive stress echocardiography } \\
(n=39)\end{array}$ & $\begin{array}{l}\text { Patients with } \\
\text { events }(n=6)\end{array}$ & $\begin{array}{l}\text { Patients without } \\
\text { events }(n=33)\end{array}$ & p Value \\
\hline \% Maximum predicted heart rate & $87.5(9.2)$ & $88.1(14.5)$ & 0.33 \\
Mean WMSI on stress echocardiography & $1.4(0.2)$ & $1.2(0.16)$ & 0.05 \\
\hline
\end{tabular}

WMSI $=$ Wall motion score index
$16.4 \%$ for women with positive stress echocardiography.

Wall motion score achieved borderline statistical significance between subgroups with and without events in the positive stress echocardiography group (table 2).

Patients with and without cardiac events did not have any overall difference in number of ischaemic coronary territories on stress echocardiography.

\section{Discussion}

This study shows that negative stress echocardiography identifies a subgroup of women with a very low annual cardiac event rate $(<1 \%)$ over more than three years of follow up, despite high pre-test probability $(\geqslant 80 \%)$ of CAD in the initial cohort. Our data also confirm the impression that clinical variables in women do not carry the same weight as they do in men, positive stress echocardiography being the only independent predictor of future cardiac events in our group of patients.

Initial assessment of patients with chest pain syndromes requires clinical risk stratification and assessment of likelihood of CAD. However, the clinical presentation, prevalence of $\mathrm{CAD}$, and role of some risk factors differs between men and women. ${ }^{134}$ Certain investigators go so far as to state that "risk factor analysis ... is of limited value in predicting coronary artery disease in women". ${ }^{6}$

It is generally desirable to undertake a non-invasive diagnostic and prognostic approach if possible, provided accuracy and tolerability are not compromised. This holds true especially in the current era of emphasis on patient outcome and cost of testing. Recently published work of Shaw et al concludes that "stable chest pain patients who undergo a more aggressive diagnostic strategy have higher diagnostic costs and greater rates of intervention and follow up costs", ${ }^{22}$

The need for a sensitive, specific, and prognostically useful non-invasive test for women with possible CAD is strong. Exercise electrocardiography is used widely in the United Kingdom as a screening and prognostic test, but has low sensitivity and specificity in women. ${ }^{6} 10^{11}$ Risk stratification can be improved by using the Duke treadmill score, ${ }^{23}$ or exercise single photon emission computed tomography. ${ }^{24}$ Exercise echocardiography has been shown to provide incremental prognostic information over exercise electrocardiography, albeit in populations of mixed gender or mixed pre-test probability of CAD. ${ }^{14}{ }^{16}$ The incremental value of stress echocardiography over stress electrocardiography in a low risk but mixed gender population has been demonstrated. ${ }^{25}$

One of the problems with exercise testing is that women are often unable to reach a sufficient workload, resulting in submaximal tests of limited sensitivity. Pharmacological stress imaging techniques have been shown to be useful for risk stratification of women with known or suspected $\mathrm{CAD}$, and are recommended by the American College of Cardiology/American Heart Association for women who are unlikely to exercise to full 
capacity. ${ }^{19}$ Geleijnse et al showed that women with chest pain and normal dobutamineatropine stress sestamibi scintigram have a good prognosis and an annual event rate of only $1.3 \%{ }^{26}$ However, their study population was not homogeneous, $65 \%$ having low or intermediate probability of CAD and $24 \%$ having known CAD. Cortigiani et al found echocardiographic evidence of ischaemia on dobutamine or dipyridamole stress echocardiography to be the only independent predictor of hard events in a group of 456 women who were not known to have CAD. ${ }^{17}$ Although their study included a large number of patients, they were not stratified into groups with different pre-test likelihood of the coronary disease, making it difficult to judge what kind of population was investigated. Such specification is especially pertinent when one takes into account the generally more benign prognosis in this group of patients. ${ }^{89}$

Unlike other authors, we did not include women with obvious resting wall motion abnormalities, as these alone have been shown to strongly indicate CAD and independently predict future cardiac events. ${ }^{15}$ We observed a lack of correlation between clinical symptoms such as angina and cardiac events. This is concordant with the fact that all forms of chest pain are associated with lower prevalence of angiographically proved CAD in women than in men. ${ }^{6927}$ Indeed, Alexander et al found that removal of the angina component of the Duke treadmill score had no impact on the score's ability to diagnose significant CAD in women. ${ }^{23}$ Similar conclusions can be drawn from other published data on investigation for coronary disease in women. ${ }^{14} 1617$

Our own previous data have shown that negative dobutamine stress echocardiography predicts excellent prognostic outcome in a relatively small but homogeneous population of women with intermediate pre-test probability of CAD. ${ }^{18}$ This study is, to our knowledge, the first to assess the prognostic value of stress echocardiography in a homogenous group of women not known to have CAD but with high pre-test likelihood $(\geqslant 80 \%)$ of CAD. We conclude that stress echocardiography is an excellent non-invasive tool for risk stratification in such a population. In particular, a negative result identifies a substantial group of patients with very low future cardiac event rate (average annual rate $0.4 \%$ ), while a positive result predicts subsequent cardiac events.

These data expand the body of evidence for the prognostic strength of stress echocardiography.

CLINICAL IMPLICATIONS

These results suggest that even for a group of women with high probability of CAD, stress echocardiography can be used with confidence as an excellent non-invasive risk stratification tool. The very low cardiac event rate for women who have a negative stress echocardiogram means that these patients can often be managed without resorting to further invasive investigation. Cost effectiveness of this approach is evident when one considers other means of diagnosis and risk stratification for CAD.

STUDY LIMITATIONS

We combined treadmill and dobutamine stress echocardiography data for this study. This represents our practice, namely that treadmill stress echocardiography is performed if it is appropriate on an individual basis. The benefits of treadmill echocardiography testing include the fact that it is a more physiological form of stress than dobutamine infusion, and may therefore more accurately represent ischaemia provoking activities encountered in real life. Problems with the treadmill approach include difficulty performing the physical activity itself, especially in such populations as this, and delayed and/or suboptimal image acquisition after exercise. Purists may feel that the two stress methods should have been considered separately, as they may have slightly different, although similar, accuracy for CAD diagnosis.

It could be argued that positive stress echocardiography and subsequent PTCA are linked, therefore the independent predictive value of positive stress echocardiography in our data could have been artificially enhanced. We tried to avoid this problem by excluding any patients who underwent elective PTCA within six months of the stress echocardiogram.

We would like to thank Dr David St George, Consultant in Clinical Information and Epidemiology, Royal Free Hospital for statistical advice.

1 Cole P. Coronary artery disease in women: differences in diagnosis, therapy, and prognosis. Coron Artery Dis 1993;4:595-604.

2 Cerqueira M. Diagnostic testing strategies for coronary artery disease: special issues related to gender. Am $\mathcal{F}$ Cardiol 1995;75:52D-60D.

3 Douglas P, Ginsburg G. The evaluation of chest pain in women. N Engl f Med 1996;334:1311-15.

4 Kennedy J, Killip T, Fisher L, et al. The clinical spectrum of coronary artery disease and its surgical and medical coronary artery disease and its surgical and medical management.1974-1979. The Coronary A
Study. Circulation 1982;66(suppl III):16-23.

5 Lerner DJ, Kannel WB. Patterns of coronary artery disease morbidity and mortality in the sexes: a 26 year follow up of the Framingham population. Am Heart $\mathcal{F}$ 1986;111:383-90.

6 Sullivan AK, Holdright DR, Wright CA, et al. Chest pain in women: clinical, investigative and prognostic features. $B M \mathcal{F}$ 1994;308:883-6.

7 Chaitman BR, Bourassa MG, Davis K, et al. Angiographic prevalence of high-risk coronary artery disease in patient subsets (CASS). Circulation 1981;64:360-7.

8 Kannel WB, Feinleib M. Natural history of angina pectoris in the Framingham Study. Am f Cardiol 1972;29:154-63.

9 Orencia A, Bailey K, Yawn BP, et al. Effect of gender on long Orencia A, Bailey K, Yawn BP, et al. Effect of gender on long term outcome of angina pectoris and myocardial infar
sudden unexpected death. $\mathscr{f} A M A$ 1993;269:2392-7.

10 Sketch MH, Mohiuddin SM, Lynch JD, et al. Significant sex differences in the correlation of electrocardiographic differences in the correlation of electrocardiographic 1975;36:169-73.

11 Kwok YS, Kim C, Grady D, et al. Exercise testing for coronary artery disease diagnosis in women: a meta-analysis. Circulation 1996;94 (suppl I):497.

12 Marwick TH, Anderson T, Williams MJ, et al. Exercise echocardiography is an accurate and cost-efficient technique for detection of coronary artery disease in women. $\mathcal{F} \mathrm{Am}$ Coll Cardiol 1995;26:335-41.

13 Sawada SG, Ryan T, Conley MJ, et al. Prognostic value of a normal exercise echocardiogram. Am Heart f 1990;120:4955.

14 McCully RB, Roger VL, Mahoney DW, et al. Outcome after normal exercise echocardiography and predictors of subsequent cardiac events: follow up of 1325 patients. $\mathcal{F ~} \mathrm{Am} \mathrm{Coll}$ Cardiol 1998;31:144-9.

15 Krivokapich J, Child J, Walter D, et al. Prognostic value of dobutamine stress echocardiography in predicting cardiac events in patients with known or suspected coronary artery disease. F Am Coll Cardiol 1999;33:708-16. 
16 Heupler S, Mehta R, Lobo A, et al. Prognostic implications of exercise echocardiography in women with known or suspected cor

17 Cortigiani L, Dodi C, Paolini E, et al. Prognostic value of pharmacological stress echocardiography in women with chest pain and unknown coronary artery disease. $7 \mathrm{Am}$ Coll Cardiol 1998;32:1975-81.

18 Davar J, Brull D, Bulugahipitiya S, et al. Prognostic value of negative dobutamine stress echo in women with intermediate probability of coronary artery disease. $\mathrm{Am} \mathrm{f}$ Cardiol 1999;83:100-2

19 Gibbons RJ, Baladay GJ, Beasley JW, et al. ACC/AHA Guidelines for exercise testing: executive summary. Circulation 1997; 96 :345-54

20 Schiller NB, Shah PM, Crawford M, et al. Recommendations for quantification of the left ventricle by twodimensional echocardiography. American Society of Echoquantification of two-dimensional echocardiograms. F Am quantification of two-dimension
Soc Echocardiogr 1989;2:358-67.

21 Bach DS, Muller DW, Gros BJ, et al. False positive dobutamine stress echocardiograms: characterisation of clinical, echocardiographic and angiographic findings. $7 \mathrm{Am}$ Coll Cardiol 1994;24:928-33.
22 Shaw L, Hachamowitch R, Berman D, et al. The economic consequences of available diagnostic and prognostic strategies for the evaluation of stable angina patients: an observational assessment of the value of precatheterisation ischemia. F Am Coll Cardiol 1999;33:661-9.

23 Alexander K, Shaw L, Delong E, et al. Value of exercise treadmill testing in women. $\mathcal{F} \mathrm{Am}$ Coll Cardiol 1998;32: 1657-64.

24 Shaw L, Hachamovitch R, Peterson ED, et al. Using an outcome based approach to identify candidates for risk stratification after exercise treadmill testing. F Gen Intern Med 1999;14:1-9

25 Colon III P, Mobarek S, Milani R, et al. Prognostic value of stress echocardiography in the evaluation of atypical chest pain patients without known coronary artery disease. $A m \mathcal{F}$ Cardiol 1998;81:545-51.

26 Geleijnse ML, Elhendy A, van Domburg RT, et al. Prognostic significance of normal dobutamine-atropine stress sestamibi scintigraphy in women with chest pain. Am f Cardiol 1996;77:1057-61.

27 Weiner D, Ryan T, McCabe CH, et al. Exercise stress testing. Correlations among history of angina, ST-segment response and prevalence of coronary artery disease in the Coronary Artery Surgery Study (CASS). N Engl f Med 1979;301:230-5

\section{7th European Forum on Quality Improvement in Health Care}

\section{1-23 March 2002 \\ Edinburgh, Scotland}

We are delighted to announce this forthcoming conference in Edinburgh. Authors are invited to submit papers (call for papers closes on Friday 5 October 2001) and delegate enquiries are welcome.

The themes of the Forum are:

- Leadership, culture change, and change management

- Achieving radical improvement by redesigning care

- Health policy for lasting improvement in health care systems

- Patient safety

- Measurement for improvement, learning, and accountability

- Partnership with patients

- Professional quality: the foundation for improvement

- Continuous improvement in education and training

- People and improvement.

Presented to you by the BMJ Publishing Group (London, UK) and Institute for Healthcare Improvement (Boston, USA). For more information contact: quality@bma.org.uk or look at the website www.quality.bmjpg.com. Tel: +44 (0)20 7383 6409; fax: +44 (0)20 73736869. 